\title{
Editorial
}

\section{Was attending the conference worth value for money?}

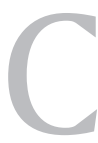

onferences organised by medical and surgical societies and related organisations are a vital feature of the academic, professional, and social life of all health-related disciplines, Plastic Surgery being no exception. These events come in all sizes, from relatively small, local gatherings, workshops, and symposia to large international mega-congresses that mobilise thousands of clinicians, researchers, exhibitors, and staff to build small-sized towns for a few days. From city chapters to state-level meetings to National and International conferences, they are a booming business and we spend time, effort and money to attend a bigname event. How do you make sure it's worth the time, effort and money?

Like any other professional encounter here too there should be a return of our investment. So let us analyse what we spend in attending a conference and what we get in return.

\section{EXPENSE INCURRED}

To attend a conference we usually spend on the following

\section{Tangible}

1. Conference registration

2. Pre/Post conference workshops/Master class/symposia

3. Material fee - book/software/media

4. Flight/Train/Taxi/personal car travel

5. Lodging - Hotel/Motel

6. Transport - airport to hotel and back, hotel to venue and back

7. Parking

8. Food

\begin{tabular}{|l|l|}
\hline \multicolumn{2}{|c|}{ Access this article online } \\
\hline Quick Response Code: & Website: \\
\hline & www.ijps.org \\
\cline { 2 - 2 } & DOI: \\
\hline
\end{tabular}

\section{Non tangible}

1. Time spent away from family

2. Effort taken to attend

3. Monetary loss for being away from clinic/hospital

4. Inconvenience to our patients

\section{RETURN OF INVESTMENT}

Many benefits from conference attendance are hard to quantify. Although networking is undoubtedly the most important aspect of a conference, it is also the toughest for which to quantify any value. You may be a regular Cleft Lip and Palate surgeon, but encounter with a top Craniofacial surgeon or an orthodontist may change your entire perspective towards the subject! Is this not priceless? You may have read everything about fat grafting, but one master class or one workshop may change your professional life! How do you put a value to this?

The icons of our specialty have routinely inspired the younger and more impressionable junior colleagues in conferences, much like a Sachin Tendulkar would do to a budding school cricketer in a stadium. So inspiration is a sure benefit and once again it is hard to put a price tag on it. However, one must be very careful in adopting the new; the most significant complications in surgery usually occur within a month of attending a conference or workshop. Many of the ideas are put into surgical practice by the juniors, without the experience and thought processes, which the experts possess. The idea is to gather the pearls but not ignore the hard work and time put in by the oysters!

Meeting authors whose books we read and questioning them directly to clear doubts can only happen in conferences. We can share ideas, challenges and plans for the future with our peers. Conferences aim to disseminate advanced research, newer technology, train, educate and set evidence-based policies. To the junior presenters of papers or posters the conference gives an immediate peer review from a hall full of audience across the intellectual spectrum. To the seniors conferences offer a branding opportunity, an occasion to build reputation 
as an outstanding hand surgeon or an excellent microsurgeon.

\section{HOW TO GET THE BEST OUT OF A CONFERENCE?}

Agreed some the conferences are well organised and some are downright awful, but how can you avoid the latter? How can you extract the maximum out of a conference? Here are my 13 pointers which I hope will help you to extract the maximum return of your investment in terms of time, effort and money, you have spent to attend a conference:

\section{Talk to people who've been to the conference before}

Preparation is crucial for using your time efficiently. If it's your first showing at a particular conference, find people who've attended it before and get them to tell you what's worth attending and what's not, as well as whom to meet.

\section{Arrive a day early so you're not groggy}

An extra night in a hotel might seem indulgent, but it can pay for itself in the value you get out of the event. Arrive on the evening before a conference starts and work from the hotel that night - give finishing touches to your presentation, read the book you have picked up in the airport and take a ward round on Skype. When everyone else at the opening reception / registration is haggard from their flights, you'll be fairly relaxed after a good night sleep and in a better state to network.

\section{Plan your day, but don't stick too closely to the plan} Spend time the night before with the conference program and book of abstracts and tick a few talks or events worth going to. This way you will plan your day well, not miss the interesting bits and not torture yourself with the chaff. Use your judgment wisely and attend the parts of the conference, which best highlight the areas of your interest or deficiencies. But, let serendipity and chance encounters guide you.

\section{Be sure your name tag is visible}

Name tags dangling from the neck are not in the line of vision. I suggest you put it on the right lapel. That puts it directly in people's line of sight when you greet them.

\section{Hang around the hospitality counter, it's a great way to meet people}

People often go to the coffee area when they've got no one to talk to. So as they're filling up it's a good time to scan their name tag and decide whether to start a conversation. Remember those delegates not sitting in the hall and listening attentively are the 'outstanding delegates' and those attending the trade stalls are the 'stalwarts'. They may not be the die-hard academicians but they are the street smart 'doers'. Respect them and extract the best out of them. These are the guys who will give you invaluable tips - how to unblock a liposuction canula, how to keep the field of micro-anastomosis dry and how to fix the medial canthus in a comminuted naso-ethmoidal fracture!

\section{Don't go to many talks, talk to people instead}

Big-name speakers may draw the crowds, but if you are not doing what they are talking about, going to their talks is like visiting an aquarium, you look at the fish and admire their beauty and antics but you cannot interact with them. Instead spend time in the hallways. It's the chance to meet lots of people with similar interests, and that's the only thing that makes a conference an irreplaceable experience. However, if you are in the hall, listening to your chosen paper be attentive and make notes - have your pen and notebook poised ready always to jot down the tips - its most important. Don't be shy even if you are a Professor yourself!

\section{Don't ignore the trade exhibition}

This is the place where you can buy the right 4 -inch scissor after testing it on your hair at the back of the hand, and liking the feel of it. Get hold of a senior colleague who does a lot of rhinoplasty and ask him to choose the best rhinoplasty set for you. Try all the available optical loupes and choose the most comfortable one in terms of clarity, magnification and working distance.

\section{Don't be shy, and don't hover}

If someone you want to talk to is standing alone, just walk up and say hello, but be sure you have something to discuss after that. Don't discuss the weather. If your target is talking to someone else, get into his field of vision from some distance away and walk up to him calmly but confidently, looking straight at him. He will usually become aware of your approach and you then have a window to interrupt politely, introduce yourself, and either join in or agree to talk later. There's nothing more irritating than having a conversation with someone else hovering on the edge.

\section{Don't just go to your hotel in the evenings}

Conference evenings are for private networking. You are still at work, just mixing it with pleasure. Talk to the 
podium presenters about their deliberations; discuss the tips and tricks with surgeon exhibiting his surgical videos. Talk to the younger surgeons about recent advances and to the trade people about newer technologies. It is your time, extract maximum value for it.

\section{Be helpful to organisers, you never know when it'll come in handy}

Get to know the organisers and try to help them out. Every conference needs last minute help in terms of arranging the inaugural ceremony, audio-visual glitches, welcoming the guests and so on. If you're a constructive member of the conference community, you may be able to suggest future conference organisers whom to invite and what to expect of him/her-and nothing builds capital with contacts like getting them invited to a conference they want to go to.

\section{Use social media to make yourself known, find people and remain in touch}

While social media is no replacement for a true handshake, we must not underestimate it. Get on with your Twitter handle and Facebook and tell people you will be attending the chosen conference. Get back to them after the conference and offer an honest appraisal. This will invariably invite a lot many opinions and responses and establish your identity as a genuine friend.

\section{Don't neglect the network you created at the conference, get in touch}

Don't attend a conference and then go back to your regular job without taking the time to reflect on it. Note down the names of the people you met by either creating a spreadsheet with the name, position, contact details and the conference at which you met the person or put all this information in your smart phone. If you have enjoyed the conference experience do not forget to thank the organisers and if you have liked a poster or a paper do not forget to convey your appreciation to the presenter.

\section{Choose your conference well, and then keep going to it}

Going to every Plastic Surgery conference is inefficient and costly. Each conference attracts a certain demographic. Choose the conference based on the type of surgery you usually do and the types of people that you're likely to meet. If cranio-facial surgery is your forte then how can you enjoy a conference on genital reconstruction or hand surgery! Once you find three or four conferences that you like, keep going back and become part of the ecosystem... People know you and you will feel welcomed.

So, while the primary onus is on conference organisers to offer a good mix of academics, camaraderie and hospitality, we too have a positive role to play in extracting maximum out of a conference. I give one star to every new thing I pick up in a conference and to me a 5-star conference is true value for my money, effort and time!

\section{Surajit Bhattacharya}

Editor

Indian Journal of Plastic Surgery

E-mail: surajitbh@yahoo.co.in

How to cite this article: Bhattacharya S. Was attending the conference worth value for money?. Indian J Plast Surg 2014;47:1-3..

Announcement

\section{“QUICK RESPONSE CODE” LINK FOR FULL TEXT ARTICLES}

The journal issue has a unique new feature for reaching to the journal's website without typing a single letter. Each article on its first page has a "Quick Response Code". Using any mobile or other hand-held device with camera and GPRS/other internet source, one can reach to the full text of that particular article on the journal's website. Start a QR-code reading software (see list of free applications from http://tinyurl.com/yzlh2tc) and point the camera to the QR-code printed in the journal. It will automatically take you to the HTML full text of that article. One can also use a desktop or laptop with web camera for similar functionality. See http://tinyurl.com/2bw7fn3 or http://tinyurl.com/3ysr3me for the free applications. 